Theme: Eletric Steelworks

\title{
DANIELI TO UPGRADE THE 150 TON EAF AT FERRIERE NORD - OSOPPO. SUCCESSFUL START-UP OF THE NEW DANARC EAF IN SCHEDULED TIME*
}

Uwe Wilhelm ${ }^{1}$

Riccardo Pasinato ${ }^{2}$

\begin{abstract}
Pittini Group has contracted Danieli in 2011 for the supply and replacement of the existing EAF at Ferriere Nord Plant in Osoppo. This was a very challenging project: giving the fact that the Meltshop was operating already under very high performance level, there were many elements involved for the project to improve (reduce the amount of charges, promote highest possible chemical energy utilization, allow best optimization on existing transformer power, modification on Drop Out box and Water Cooled Duct, Hydraulic System for EAF, Scrap Bucket design to fit to new EAF with existing loading and transport system, Automation System Review and Upgrade) as well as limitations of the existing installation (limited space, lifting capacity building and cranes and the required solutions for fast shell and roof exchange). All furnace parts, as well as installation engineering, were developed and discussed carefully with the Customer to either provide proven and reliable concepts, but also to define solutions for fast installation/maintenance access and quick exchange for offline turnaround. In the end, from disassembly of existing equipment up to the first heat of the new furnace, only 38 days were necessary. First heat was made on January 24th 2013, on the 6th production day 32 heats where produced at nominal design capacity and 28 days after start up 100,000 t liquid steel have already been produced.
\end{abstract}

Keywords: Melt shop modernization; EAF revamp; Steel making; Melt shop logistic; Raw material preparation.

1 Engineer, VP, Danieli Service, Rheinfelden, Switzerland; u.wilhelm@swiss.danieli.com.

2 Engineer, Executive Manager, Danieli Centro Met, Rheinfelden, Switzerland; r.pasinato@swiss.danieli.com.

* Technical contribution to the $45^{\text {th }}$ Steelmaking Seminar, May $25^{\text {th }}-28^{\text {th }}, 2014$, Porto Alegre, RS, Brazil. 


\section{PROJECT DESCRIPTION}

Ferriere Nord is located in Ossopo, in the Northeast part of Friuli/ltaly. The Steelplant is operating, based on an Electric Arc Furnace, for the production of Long Product steel for two rolling mills, one rolling mill for wire rod and another for reinforcing bars. In order to improve the Melting side of the production, Ferriere Nord has decided to replace the existing Arc Furnace to improve the operation as well as maintenance aspects. The project has been concluded in between Ferriere Nord and Danieli Centro Met in September 2011.

Several objectives for the revamp have been specified by Ferriere Nord as mandatory elements for the revamp in order to improve operational as well as maintenance parameters, both in terms of cost and quality. It was very clear for Danieli that right from the beginning a comprehensive team approach has to be undertaken to be able to follow professionally the requirements defined for this project.

Danieli has mobilized the necessary experts with the Product lines involved in the project:

- Danieli Centro Met

- Danieli Environment

- Danieli Automation

The Scope of the Project can be summarized:

- New EAF Mechanic, 150t capacity, 6.800mm diameter

- New EAF Hydraulic System

- New Buckets and Transfer Cars Modification

- Upgrade of existing Injection Technology for the new requirements

- New Drop Out Box / Water Cooled Duct with Hot Water Cooling

- New 3Q Automation Concept

- New HiReg Electrode Regulation

- New EAF Foundations incl. Tapping Pit,

- Modifications on Furnace Floor and Slag Pit

- Others / Auxiliaries in the surrounding of the EAF.

Several meetings in the proposal phase, as well in the engineering phase, have been undertaken jointly between Ferriere Nord and Danieli teams to select the best option, in some areas a unique path has been taken to satisfy the targets set in force. Due to the expertise in all teams, the solutions defined jointly have been proven to be on the right way as it has been seen in the operational practice after EAF start up.

After completion of engineering phase, both teams worked closely together, monitoring the overall project progress and the expected quality for each functional unit. Most of the fabrication was within a short driving range making this exercise feasible and affordable from a time viewpoint. The equipment was fabricated and preassembled as much as possible, allowing all major part being supplied in a "ready to install" condition.

All the engineering has been built in a comprehensive 3D model and all movements, in terms of speed and synchronization, have been simulated virtually with the 3D model in order to fully understand and agree before the equipment will be set in production: doing so, the fine-tuning during commissioning and start up was limited and the ramp up nearly instantaneous. The 3D model was also developed with necessary care related to the on board as well as field piping within scope, allowing

* Technical contribution to the $45^{\text {th }}$ Steelmaking Seminar, May $25^{\text {th }}-28^{\text {th }}, 2014$, Porto Alegre, RS, Brazil. 


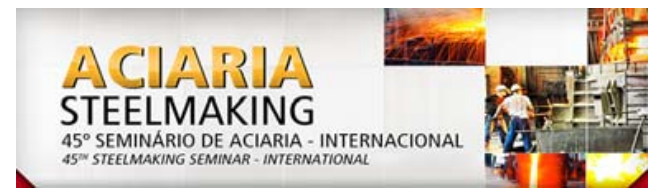

the maximum piping preparation during fabrication and then reducing the installation to minimum.

Project management, from both Ferriere Nord and Danieli's side, have been working very hard to be on top of all activities and to foresee any possible change in the project development. Due to excellent and instantaneous communication all fabrication and procurements was on time.

The major Milestones during shutdown where:

- $\quad$ Start EAF Disassembly: 17.12.2012

- New Foundation ready for EAF erection: 26.12.2012

- Mezzanine for DOB Installation ready 03.01.2013

- End Erection, Start Cold Test, 15.01.2013

- End of Cold Test: 21.01.2013

- First Heat: 24.01.2013

Production reached soon high level:

- $\quad$ 1st 24hr Production: 26.01.2013

- 1 st 32 heats/day produced, 6th day, 29.01.2013

- 1 st 100.000t produced, 20.02.2013 (28th day after first heat)

- 1st 1.000.000t produced, 27.10.2013 (incl. 3 Weeks annual shutdown)

Performance Reached: (Averaged out of 3000heats until May, all parameters related to good billets).

Table 1. Title

\begin{tabular}{|l|c|}
\hline Power on Time: & $38,2 \mathrm{~min}$ \\
\hline Total Power Off time (including All Delays) & $7,8 \mathrm{~min}$ \\
\hline Delays (Total at EAF) & $2,5 \mathrm{~min}$ \\
\hline Average ttt & $46 \mathrm{~min}$ \\
\hline Average Weight, Good Billets / heat & $129 \mathrm{t}$ \\
\hline Electrical Consumption (Depending on program and charge mix) & $355 \div 385 \mathrm{kWh} / \mathrm{t}$ \\
\hline Electrode consumption & $1,25 \mathrm{~kg} / \mathrm{t}$ \\
\hline
\end{tabular}

\section{TECHNICAL CHARACTERISTICS}

Main Data:

- $150 t$ total capacity liquid steel

- $6.800 \mathrm{~mm}$ EAF diameter

- Nominal Tap Weight $127 \mathrm{t}$

- Electrode Diameter 711mm / 28"

- Single Point Roof Lifting with self-supporting roof frame, extended stroke

- Ultra High Power Chemical Energy package

- Transformer 100/120 MVA Transformer

- Quick Shell / Roof Exchange Technology with Offline Maintenance

- Quick DOB exchange with transfer car

\subsection{Description of Equipment}

The new EAF is a full platform furnace latest generation. The selected solution has been defined mainly to fit into limited space in width and height, still allowing:

- High Shell design

- Ultra Fast movements

- Good visibility and safe access for operation and maintenance

* Technical contribution to the $45^{\text {th }}$ Steelmaking Seminar, May $25^{\text {th }}-28^{\text {th }}, 2014$, Porto Alegre, RS, Brazil. 
Specific attention has been paid to:

- Electrode and Roof Lifting and rotation unit

- Electrode Arms / Columns design

- Secondary System with Power Cable

- Shell Design

- DOB Design

\subsection{Electrode and Roof Lifting and Rotation Unit}

Due to the limited space, as well as due to requirements for Ultra Fast movements, a non-standard solution has been selected for the whole unit. However, thanks to this solution, several details have been identified to be superior for the operation as well for the reliability of the equipment. I.e. clearance bucket to the whole structure is higher for lower risk of damage through mechanical and thermal influence.

Due to the kinematic of the unit, cable length can be defined shorter which reduce total reactance for more power input. Furthermore cable sway and twist are reduced for longer cable life. The rotation unit has been designed as high capacity roller bearing for the Ultra Fast speed and simplification for maintenance and replacement.

\subsection{Electrode Arms / Columns design}

The electrode arms are in coplanar arrangement which offers the following advantages:

- all cable connections are on the same plane in level and distance, such the permanent implementation of a service platform towards transformer wall is possible and beneficial. By this platform, maintenance can now reach the cable terminals at any time and safely, on both side to the arms and transformer secondary system.

- due to existing crane rail, being above the tail end of the electrode arm, the possibility of a triangulated arrangement for phase-II was not possible. With this configuration, all three phases reach in the raised position the highest possible level: that allowed making the shell as height as geometrically possible.

The columns have been dimensioned in position as close as possible towards the furnace, reducing the cantilever effect and related electrode vibration; the roller arrangement for the mast guides is prismatic with easy to adjust eccentric shafts. The masts are made with Hardox rail so the service life is extended.

\subsection{Secondary System with Power Cable}

Due to the overall resulting reactance balance driven by the electrode arm coplanar arrangement, the secondary system had to be specifically designed to allow the phase-II reactance compensation. This has been realized in an innovative solution, that still allowed a coplanar bas bar arrangement outside the transformer room, especially as there is a crane rail girder limiting access options. The selected solution has been proven to make the system perfectly balanced with the result in a homogeneous condition related to hotspots inside the furnace.

* Technical contribution to the $45^{\text {th }}$ Steelmaking Seminar, May $25^{\text {th }}-28^{\text {th }}, 2014$, Porto Alegre, RS, Brazil. 


\subsection{Shell Design}

The shell has been designed for full shell exchange practice. The shell is designed with EBT lower shell and a cage frame upper shell with panels. All panels are designed for reliable configuration, easy exchange and some specific innovations: such the shell campaign is never interrupted by panel failure during the operation and any repair or maintenance is done offline during the relining activities.

Due to these requirements and in order to reuse existing cooling water supply conditions, from the existing water treatment plant, a unique distribution concept has been selected. All Injectors and burners installed on the lower area of the shell are embedded in full copper pipe panels, the upper portion of the shell in steel pipe panels. Danieli's tap hole paddle is designed not only assuring a safe closing and opening cycle during the operation, but also allowing mechanical tap hole cleaning right after tapping.

\subsection{Drop Out Box Design}

The EAF primary off-gases are directly collected into floor based drop out box, with movable inlet duct. Due to the characteristics of the EAF process at $F N$, the combustible rate inside the off-gas fumes required a large chamber installed in between the melting bay and the parallel auxiliary bay. In order to allow maintenance of the DOP with bay overhead crane, it has been decided to install the DOB on a transfer car. This will shorten maintenance activities significantly, as far as required. Due to the gas flow and position of inlet and outlet duct, fluid dynamical simulations have been performed to make the DOB most efficient in dust drop out and gas cooling.

The bottom of the drop out box has fixed cones and discharge system, to avoid extensive shutdown requirements for cleaning. A further advantage: the continuous discharge is combined with direct dust / slag recycling to eliminate disposal and for partial recovery in EAF process.

\section{ENGINEERING AND PROCUREMENT}

Engineering of the project started in November 2011 and was finalized during spring / summer 2012. Common review meetings ensured that all was within projected scope and according to specifications. This part was a very intense cooperation between Ferriere Nord operation/maintenance and Danieli Technical offices, allowing to develop specific solutions for fast/efficient operation, easy installation, reliability during operation and quick access/exchange if necessary in case of failure.

The entire project was developed in 3D to check and solve all possible interferences with the existing infrastructure, to have the correct piping route for skid preparation having benefits during the erection activities.

The project engineering was done jointly between Danieli's divisions and the project team of Ferriere Nord. All parts where 3D modeled to greatly improve

- Equipment dimensioning

- Virtual Movements and set up

- Piping Engineering

- Collision prediction.

* Technical contribution to the $45^{\text {th }}$ Steelmaking Seminar, May $25^{\text {th }}-28^{\text {th }}, 2014$, Porto Alegre, RS, Brazil. 

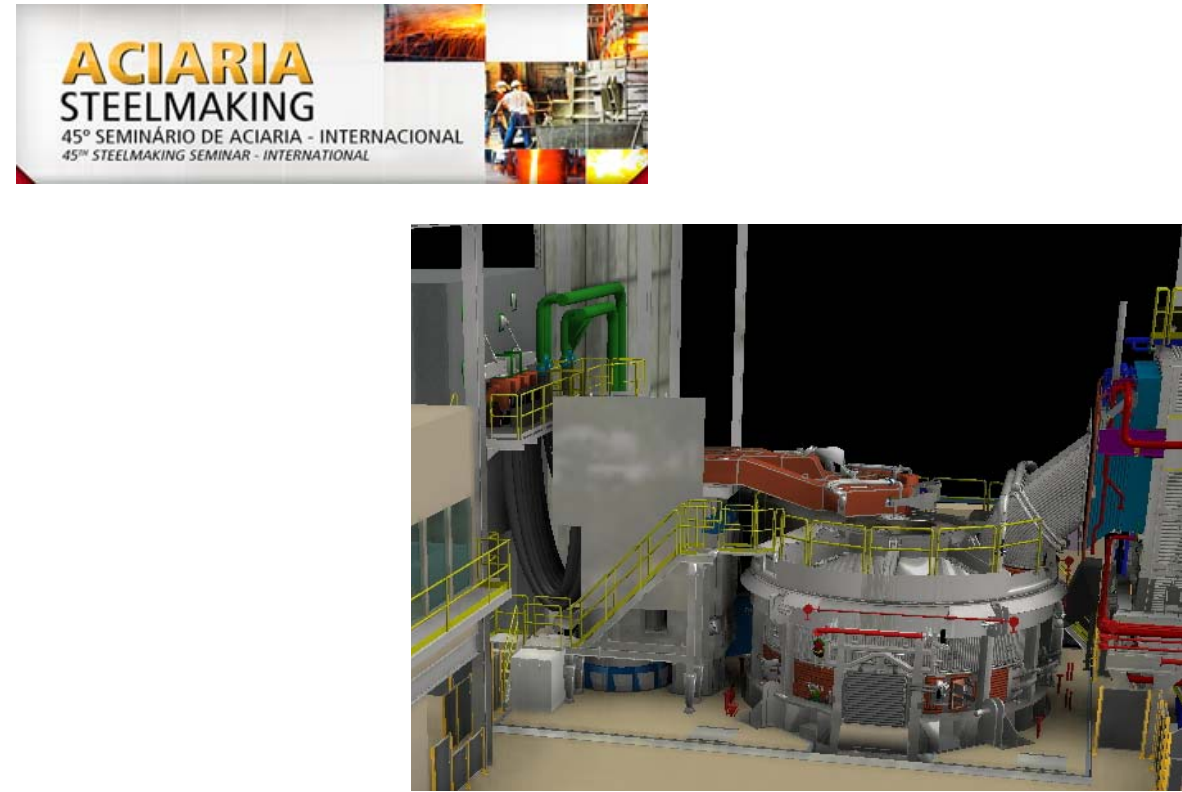

Figure 1. Engineering View and Actual View at slag door side 1.

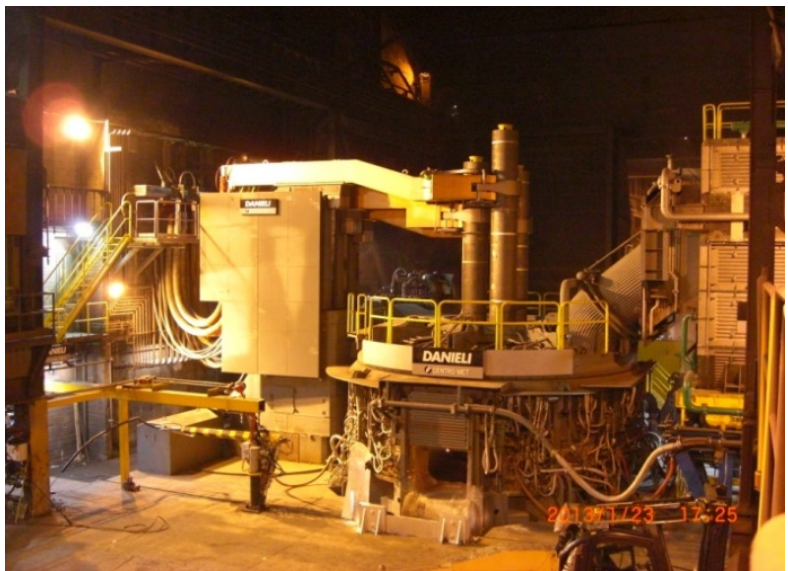

Figure 2. Engineering View and Actual View at slag door side 1.

All main furnace parts were manufactured in the area, for close follow up and entire workshop assembly and testing. Workshop acceptance tests were carried out between Ferriere Nord and Danieli and then the parts were shipped to site in Osoppo, before the plant shut down. Hydraulic system was completely preassembled and erected inside the workshop within the dimension of the actual hydraulic room with all inlet/outlet manifolds for a fast a precise erection on site (Figures 3 and 4).

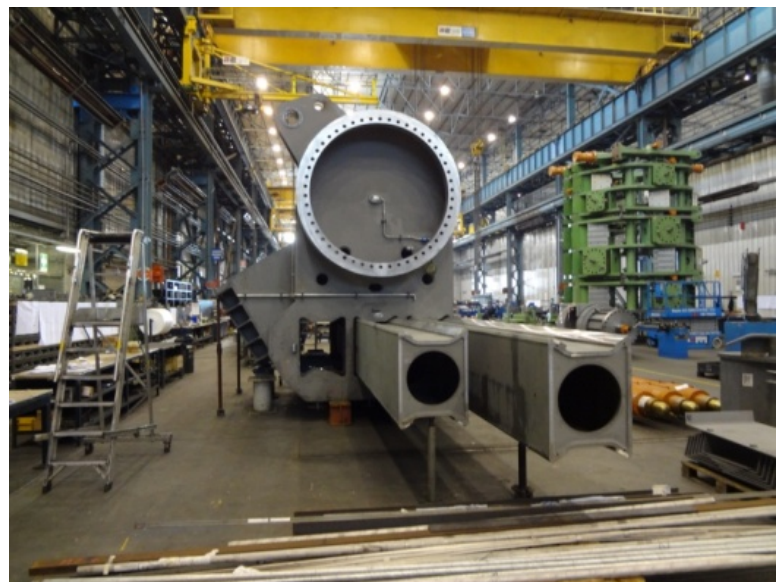

Figure 3. Workshop preassembly gantry and Workshop preassembly hydraulic unit.

* Technical contribution to the $45^{\text {th }}$ Steelmaking Seminar, May $25^{\text {th }}-28^{\text {th }}, 2014$, Porto Alegre, RS, Brazil. 

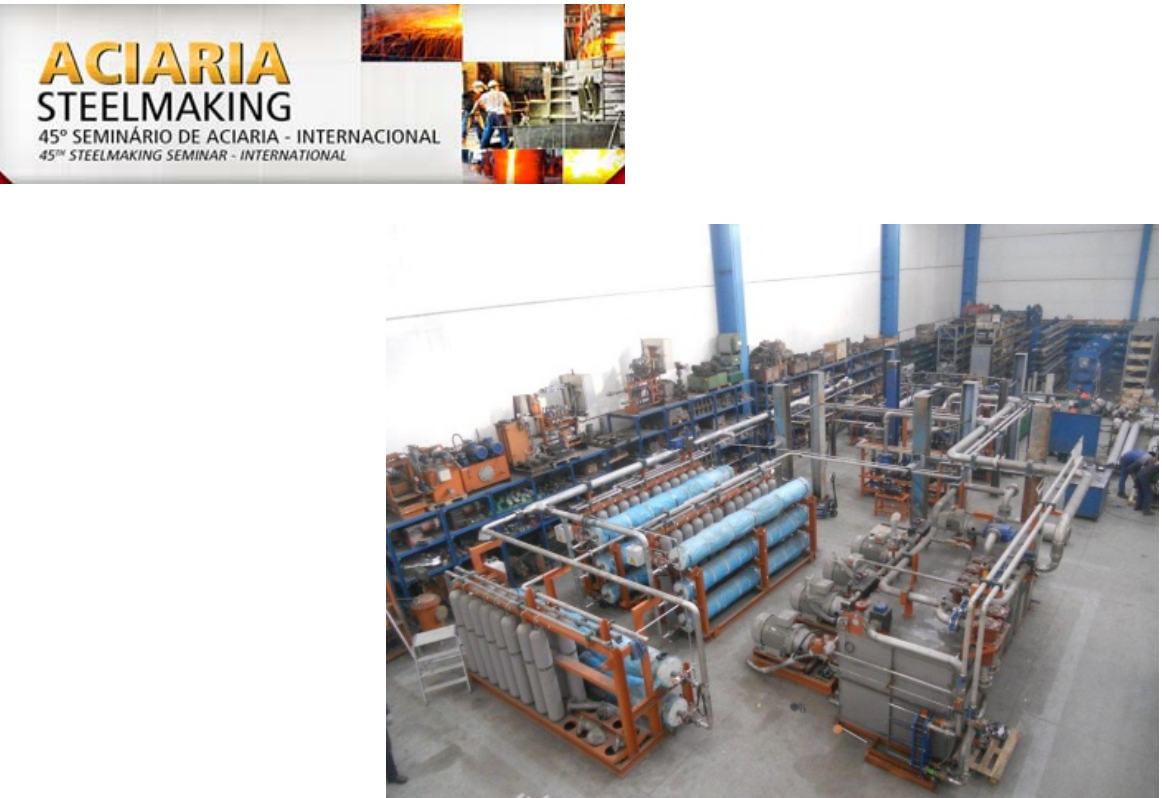

Figure 4. Workshop preassembly gantry and Workshop preassembly hydraulic unit.

\section{ELECTRIC AND AUTOMATION}

The Automation Package is replacing the existing Hard and Software Systems to provide a working environment with State of the Art Interfaces, Ergonomy and Layout. A completely new 3Q System developed by Danieli Automation has been considered and the complete Automation system was Factory tested between Danieli Automation and Ferriere Nord Automation departments in Danieli Automation workshops before releasing the equipment to site.

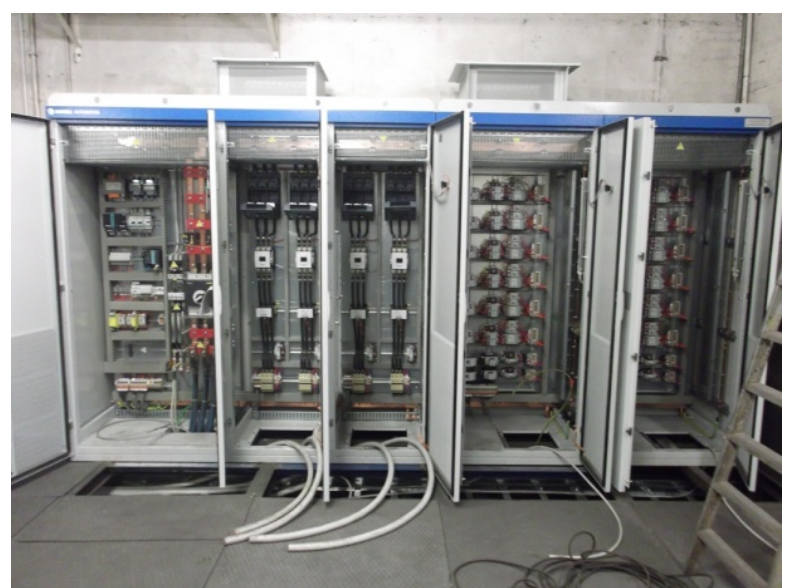

Figure 5. LV Switchboards and PLC Switchboards.

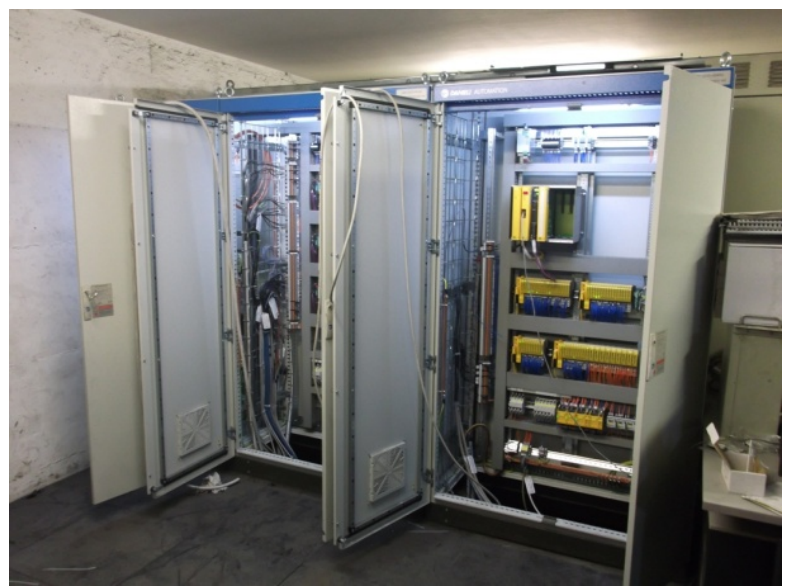

Figure 6. LV Switchboards and PLC Switchboards.

* Technical contribution to the $45^{\text {th }}$ Steelmaking Seminar, May $25^{\text {th }}-28^{\text {th }}, 2014$, Porto Alegre, RS, Brazil. 

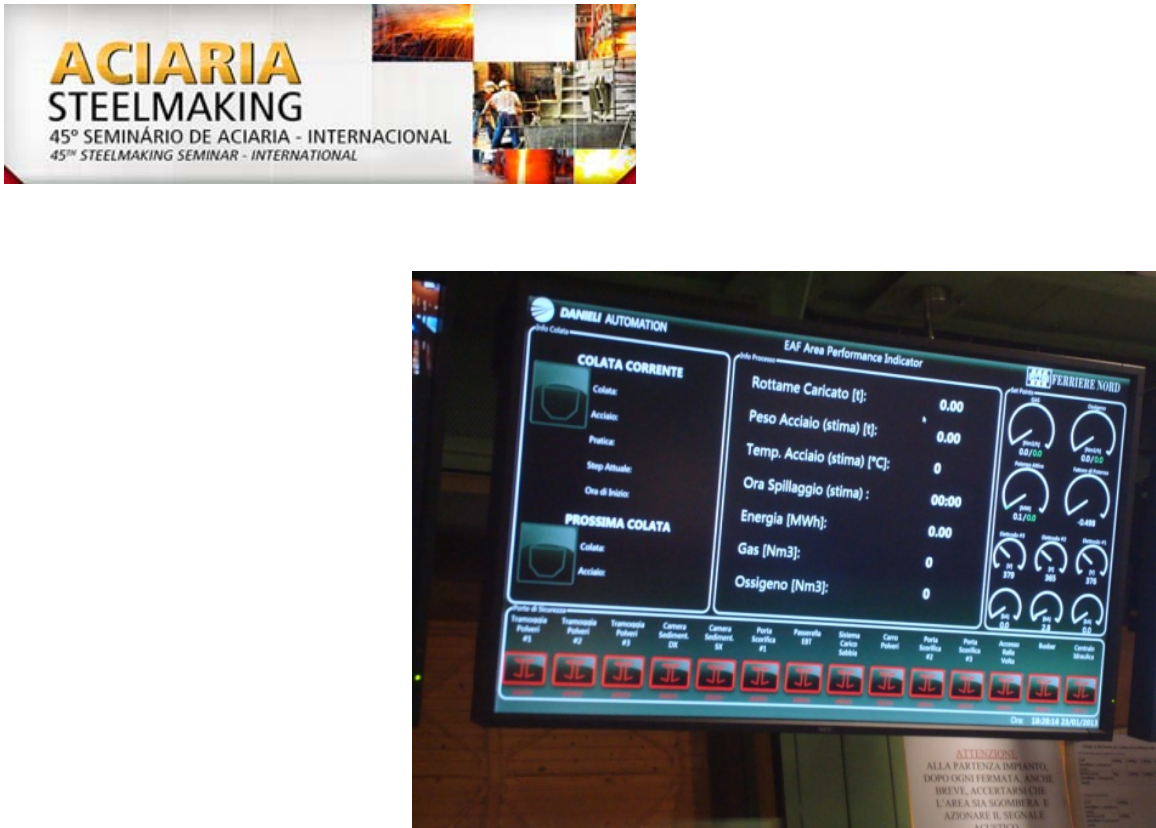

Figure 7. PPI: Plant Performance Indicator and OA: Operator Assistance.

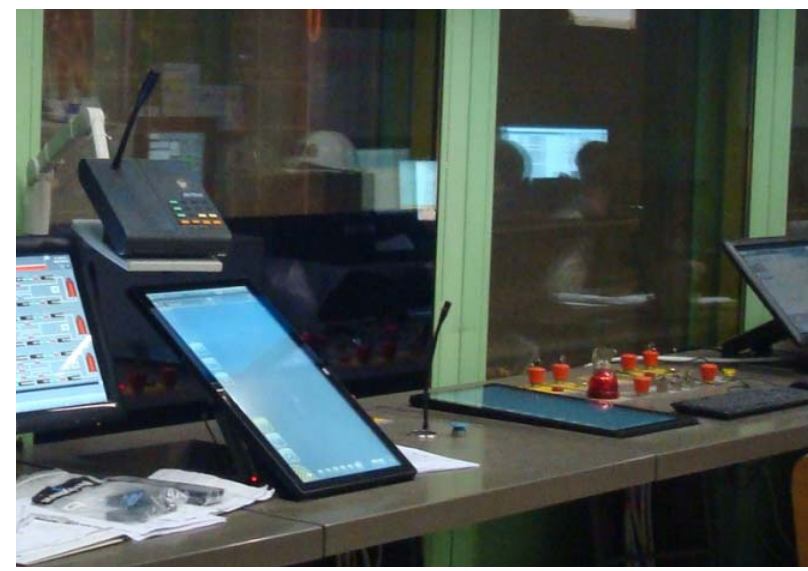

Figure 8. PPI: Plant Performance Indicator and OA: Operator Assistance.

\section{SUMMARY}

Ferriere Nord and Danieli Centro Met have concluded the EAF revamp project in September 2011, Engineering, Procurement and Manufacturing was through 2012, installation and commissioning was in January 2013, total project time was 16 month. The overall results have proven to be in-line with commitments given from both sides in technical terms, as well as in execution time and quality.

38 days was the total necessary time for the complete EAF replacement, including foundation activities and field piping: it has been challenging, but it has also been proven to be possible with a close team approach.

Furthermore, this project has demonstrated that, even though short time is available for testing during outage, the equipment is reliable from the beginning. That thanks to engineering commitments and to high degree of Work Shop assembling and testing, of mechanical and hydraulic equipment's, as well as of the automation part.

When the furnace has been starting $24 \mathrm{hrs}$ production, the level reached soon after was inline with expectation and nominal capacity.

* Technical contribution to the $45^{\text {th }}$ Steelmaking Seminar, May $25^{\text {th }}-28^{\text {th }}, 2014$, Porto Alegre, RS, Brazil. 